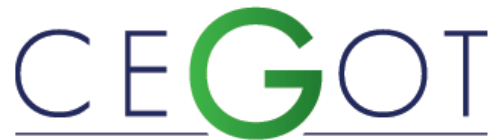

Centro de Estudos de Geografia e Ordenamento do Território
Geografia e Ordenamento do Território, Revista Eletrónica Centro de Estudos de Geografia e Ordenamento do Território http://cegot.org

ZANATTO, VinícIUS

Universidade de Brasília, Instituto de Ciências Humanas,

Departamento de Geografia

Universidade de Brasília, Campus Darci Ribeiro, 70910-900 Brasília, Brasil

vini.galvaozanatto@gmail.com

STEINKE, VALDIR

Universidade de Brasília, Instituto de Ciências Humanas,

Departamento de Geografia

70910-900 Brasília, Brasil

valdirsteinke@gmail.com

VIEIRA, ANTÓNIO

Universidade do Minho, Instituto de Ciências Sociais,

Departamento de Geografia, CEGOT

4800-058 Guimarães, Portugal

vieira@geografia.uminho.pt

\title{
Impactos do geoturismo na caverna Terra Ronca, Goiás, Brasil
}

\section{Geotourism Impacts in Terra Ronca Cave, Goiás, Brazil}

Referência: Zanatto, Vinícius; Steinke, Valdir; Vieira, António (2019). Impactos do geoturismo na caverna Terra Ronca, Goiás, Brasil. Revista de Geografia e Ordenamento do Território (GOT), n. ${ }^{\circ} 16$ (março). Centro de Estudos de Geografia e Ordenamento do Território, p. 391-414, dx.doi.org/10.17127/got/2019.16.017

\section{RESUMO}

A prática do geoturismo tem-se disseminado e multiplicado, pela sua capacidade de promoção de um verdadeiro conhecimento dos valores da geodiversidade dos diferentes territórios, potenciando ainda o desenvolvimento de áreas dotadas de elevado e diversificado valor geomorfológico, geológico e demais elementos abióticos. Porém, esse desenvolvimento não tem sido realizado sem que ocorram impactos significativos sobre essa mesma geodiversidade e sobre as próprias comunidades locais. O presente trabalho tem como objetivo identificar e caracterizar os impactos do geoturismo na região de Terra Ronca, nomeadamente na principal caverna, também designada de Terra Ronca. Os procedimentos adotados consistiram na aplicação de um protocolo de avaliação rápida de impactos sobre os ambientes cavernícolas, complementado com entrevistas à população local e pessoas envolvidas na gestão das unidades de conservação e apoiado em revisão bibliográfica. Os resultados demonstraram que o geoturismo vem sendo desenvolvido de maneira desordenada, possibilitando a perda da geodiversidade local.

Palavras-chave: Avaliação de Impactos, Geodiversidade, Parque Estadual de Terra Ronca, Unidades de Conservação, Geopatrimônio.

\section{ABSTRACT}

The practice of geotourism has been disseminated and multiplied, by its ability of promote a true knowledge of the geodiversity values present in the different territories, increasing the development of areas with high and diversified value in terms of geomorphological, 
geological and other abiotic elements. However, this development has not been carried out without significant impacts on geodiversity and on local communities. The present work aims to identify and characterize the impacts of geotourism in the region of Terra Ronca, namely in the main cave, also called Terra Ronca. The procedures adopted consisted in the application of a protocol for rapid assessment of impacts on cave environments, complemented by interviews with the local population and people involved in the management of conservation units and supported by a bibliographic review. The results showed that geotourism has been developed in a disordered way, allowing the loss of local geodiversity.

Keywords: Impact Assessment, Geodiversity, Terra Ronca State Park, Conservation Units, Geoheritage.

\section{Introdução}

O estabelecimento de áreas protegidas, que no Brasil têm a designação de Unidades de Conservação (UC), tem sido considerado como um dos principais instrumentos para a defesa da biodiversidade e da geodiversidade no mundo, ainda que no caso desta última, apenas muito recentemente. Efetivamente, a geodiversidade foi, durante muito tempo, relegada para segundo plano nas iniciativas de conservação da natureza (VIEIRA, 2008, 2014), sendo que tem vindo a ser progressivamente considerada e incluída a sua conservação nos planos de áreas protegidas ou por meio da promoção de áreas específicas para a geoconservação (Geoparques).

Tal como a biodiversidade, também a geodiversidade proporciona diversos serviços ambientais (ou ecossistêmicos), no contexto das funções de regulação, provisionamento, conhecimento, cultura e de suporte (GRAY, 2011; GORDON e BARRON, 2013). Os elementos contidos na geodiversidade proporcionam o suporte para que a vida ocorra (portanto, serviços de suporte), fornecem recursos minerais e energia (serviços de provisionamento) e, além de guardarem os testemunhos da história da evolução da Terra (serviços de conhecimento), são responsáveis por manter as dinâmicas e processos que ocorrem nos diversos ecossistemas (serviços de regulação), possuindo também capacidade para potenciar o desenvolvimento local, em especial, por meio do geoturismo (serviços culturais).

No Brasil as unidades de conservação são categorizadas em dois grupos: as de uso sustentável, que permitem uma elevada variedade de atividades antrópicas, desde que 
estejam previstas no seu respetivo plano de manejo; e as de proteção integral, que possuem restrições no que diz respeito aos usos e ao acesso às áreas demarcadas.

Uma das atividades econômicas que procura explorar as potencialidades paisagísticas das Unidades de Conservação é o turismo. Dentre os diversos segmentos turísticos desenvolvidos ao longo das últimas décadas, o Turismo de Natureza destaca-se por se basear no aproveitamento dos recursos naturais balizado em princípios de sustentabilidade, no qual a diversidade da natureza nos seus diferentes elementos é razão para o desenvolvimento de atividades de visitação, sem colocar em causa a sua preservação. A maioria das pessoas que optam por esse segmento tem como objetivo a procura de uma relação direta com a natureza e são atraídas pelo fato de poder estar em pleno contato com ela.

O Geoturismo, pelo facto de utilizar determinados recursos naturais enquanto recurso/produto turístico, especificamente centrado no conceito de geodiversidade e nos valores inerentes aos elementos geomorfológicos, geológicos, pedológicos e demais componentes da geodiversidade, tem vindo a integrar-se genericamente neste segmento de turismo.

Hose (1995) considerou o geoturismo como "a provisão de serviços e facilidades interpretativas que permitam aos turistas adquirirem conhecimento e entendimento da geologia e geomorfologia de um sítio (incluindo sua contribuição para o desenvolvimento das Ciências da Terra), além de mera apreciação estética". Trata-se de uma definição que ainda que restritiva quanto aos elementos considerados, integra os aspetos fundamentais em que se baseia o geoturismo.

Por outro lado, Stanley (2000: 16) defende que o geoturismo se baseia essencialmente no caráter geológico, o qual se constitui como base para a vida na Terra. Nesse sentido, segundo este autor o geoturismo busca um contato com a riqueza natural, ligada diretamente aos processos da história geológica da Terra.

Azevedo (2007: 23), seguindo um pouco o principio orientador do conceito proposto por Stanley, define geoturismo como sendo: "um segmento da atividade turística que tem o patrimônio geológico como seu principal atrativo e busca sua proteção por meio da conservação de seus recursos e da sensibilização do turismo, utilizando, para isto, a interpretação deste patrimônio tornando-o acessível ao público leigo, além de promover a sua divulgação e o desenvolvimento das ciências da Terra". 
Na mesma linha restritiva, por considerar apenas uma parte da geodiversidade, Nascimento et al. (2007) referem que "o geoturismo compreende um novo segmento do turismo de natureza, no Brasil, que surge com a intenção de divulgar o património geológico".

Numa perspetiva mais abrangente e integradora, Dowling (2010) refere que o geoturismo pode ocorrer num variado espectro de ambientes, promovendo a conservação do geopatrimônio por intermédio de medidas sustentáveis apropriadas, avançando no entendimento geológico e geomorfológico por meio da interpretação e educação, gerando a satisfação no turista ou visitante.

Rodrigues (2009) põe a ênfase na consideração do geopatrimônio (que incorpora o patrimônio geomorfológico, o patrimônio geológico, o patrimônio hidrológico e outras formas de patrimônio abarcadas pelo conceito de geodiversidade) enquanto objeto de usufruto sustentado por parte do geoturismo, incluindo quer os geoturistas, quer as populações locais, acrescentando a importância de se lhe agregar o patrimônio cultural.

Esta é uma perspetiva mais integradora, com a qual concordamos, que potencializa as várias formas de patrimônio abiótico para o usufruto por parte dos geoturistas, assegurando a valorização das iniciativas promotoras do desenvolvimento em favor da comunidade local.

Dessa forma, o geoturismo aborda o conceito de geopatrimônio de uma determinada região ou lugar não apenas como objetos de observação e apreciação, mas como elementos de compreensão e conhecimento dos processos relacionados com a evolução do planeta.

A gestão das atividades turísticas em áreas protegidas requer um sólido conhecimento científico sobre o ambiente direta e indiretamente afetado por tais atividades (LOBO et al., 2015). Concomitantemente, deve ocorrer um acompanhamento contínuo dessas atividades e uma avaliação baseada em critérios rigorosos e adaptados a cada situação, por forma a implementar-se um monitoramento dos impactos, seu seguimento, e implementação de medidas de mitigação, sempre que necessário.

Considerando-se a região de Terra Ronca, detentora de importante riqueza e diversidade geopatrimonial, nomeadamente a relacionada com geomorfologia cárstica, mormente pela presença de diversas cavernas, considerámos a sua utilização como objeto de estudo no presente trabalho.

Assim, o objetivo deste artigo foi o de caracterizar a prática geoturística que ocorre na região de Terra Ronca, bem como seus impactos sociais e sobre os ambientes cavernícolas, especificamente o da caverna Terra Ronca. 
Os procedimentos adotados para a realização do estudo consistiram, numa fase inicial, na revisão bibliográfica relativa à temática em análise e ao território selecionado para o estudo, a que se sucedeu o levantamento de dados espaciais, o trabalho de campo com aplicação de protocolo, visando a avaliação dos impactos causados na caverna Terra Ronca, e entrevistas com a população local.

Este artigo integra a pesquisa denominada "Avaliação de Efetividade de Gestão de Três Unidades de Conservação do Nordeste Goiano", conduzida no âmbito do Programa de PósGraduação em Geografia da Universidade de Brasília. Portanto, o resultado presente neste trabalho é parcial e visa demonstrar a aplicação de protocolos de avaliação como uma ferramenta capaz de auxiliar em diagnósticos ambientais e priorização de ações para conservação de cavernas em áreas protegidas.

\section{2. Área de Estudo}

A área de estudo da pesquisa localiza-se na região de Terra Ronca, no estado de Goiás, Brasil (Figura 1).

Encontra-se localizada na Bacia hidrográfica do rio Paranã, que é uma sub-bacia do rio Tocantins (HERMUCHE, 2010).

$\mathrm{Na}$ área pesquisada há uma variação de altitude significativa em relação ao nível do mar, entre 400 e 1000 metros. As maiores altitudes são encontradas na parte leste, próximas à Serra Geral de Goiás, enquanto a oeste são encontradas as menores altitudes. A maior parte da região de estudo concentra altitudes entre 700 e $750 \mathrm{~m}$. Desta maneira os relevos intermediários conectam-se aos níveis superiores através de escarpas e rebordos, demonstrando o acentuado trabalho erosivo, que é evidenciado pela presença de relevos residuais na frente das escarpas (IBGE, 1995).

Este território está inserido numa depressão no Planalto do Divisor do São Francisco Tocantins, ou seja, no divisor de águas da bacia dos rios São Francisco e Tocantins. A área situa-se na borda do Chapadão Central. Há predominância de modelados de dissolução, que esculpem relevos ruiniformes nas rochas calcárias, em forma de corredores e rampas dissecadas e topos tabulares e convexos (IBGE, 1995). A presença de relevo cárstico 
proporciona o surgimento de sumidouros e grutas. Estes estão presentes na parte oriental da Serra Calcária, enquanto as ressurgências se situam na parte ocidental da serra.

A maior parte é formada por pediplano retocado desnudado, existem áreas de acumulação coluvial próximas as vertentes da Serra Geral de Goiás e dissecação homogênea nas vertentes. Na parte central da área de estudo está presente a serra calcária formada pelo sistema Cárstico - Pelítico Guarani de Goiás-Divinópolis de Goiás (IBGE, 1995).

A área de estudo da pesquisa compreende três unidades de conservação, localizadas nos municípios de São Domingos e Guarani de Goiás, na região nordeste do estado de Goiás, Brasil. Historicamente esta região é considerada como a menos desenvolvida social e economicamente do estado de Goiás (CARVALHO, 2004, 2005; NUNES, 2013). Entretanto, é reconhecidamente detentora de uma significativa riqueza natural e cultural, que foi preservada pelo "isolamento" econômico e a falta de políticas adequadas para o desenvolvimento da região (CARVALHO, 2005).

A UC do Parque Estadual de Terra Ronca - PETER foi legalmente criada em julho de 1989, possuindo 56.982 ha. Um dos objetivos do PETER é preservar as cavidades naturais, que vão abrigar uma ampla quantidade de espécies endêmicas e desenvolver ecossistemas e habitats específicos.

Relativamente à Reserva Extrativista do Recanto das Araras de Terra Ronca, foi estabelecida em setembro de 2006, com 11.964 ha. A RESEX Recanto das Araras de Terra Ronca tem como objetivo garantir a manutenção dos recursos naturais necessários para conservar meios de vida da população que vive do extrativismo, da criação de animais e da agricultura de subsistência.

A Área de Proteção Ambiental da Serra Geral de Goiás foi criada em 1996, com 49.058 ha. A APA tem como principal objetivo proteger a área no entorno do PETER, funcionado como uma zona de amortecimento, regulando o uso da terra.

A área de estudo compreende diversas fitofisionomias do bioma Cerrado. Cada uma destas formações vegetais tem sua importância dentro do sistema estudado. No entanto, as formações denominadas como Floresta Estacional Decidual e Floresta Estacional Semidecidual, também conhecidas como matas secas, possuem relações muito próximas com os ambientes associados às cavernas.

A região definida para o estudo (Figura 1) concentra uma grande quantidade de cavernas, sendo que só o município de São Domingos possui 101 cavernas catalogadas, estando entre 
os 10 municípios com maior ocorrência de cavernas do Brasil (CNC, 2016). Visto isso, pesquisas sobre o estado de conservação das cavernas são importantes para se pensar o desenvolvimento econômico e social da região.

A área de estudo possui diversas características geológicas e geomorfológicas de realce (Figura 1), que apresentamos, seguindo a classificação estabelecida por Moraes (2014), na publicação "Geodiversidade do Estado de Goiás e do Distrito Federal".

Na borda da Serra Geral de Goiás identifica-se o "Domínio dos Sedimentos Cenozóicos e/ou Mesozóicos, pouco a moderadamente consolidados, Associados a Profundas e Extensas Bacias Continentais (DCM)", que compreende uma faixa estreita localizada no limite com o estado da Bahia, e que é composto por arenitos e siltitos da formação Urucuia, de idade cretácea superior, em que predominam relevos dos tipos chapadas, platôs e planaltos seguido de relevos residuais devido ao caráter sedimentar das rochas de que é formado (MORAES, 2014).



Figura 1 - Domínios geológicos - Terra Ronca - Goiás - Brasil. Fontes: IBGE, MMA, ICMBio, USGS. Elaboração: Vinícius Galvão Zanatto. Julho 2017. 
Na base da Serra Geral encontramos o "Domínio de Sedimentos Indiferenciados Cenozoicos Relacionados ao Retrabalhamento de Outras Rochas (DCSR)". Este domínio é formado por camadas horizontalizadas e assentes sobre superfícies de aplainamento de diversas espessuras que foram depositadas no Cenozoico. São sedimentos clásticos provenientes das formações Cachoeirinha, Coberturas Arenosas Indiferenciadas e Depósitos Colúvio-eluviais. O domínio apresenta-se sutilmente elevado com relevo em forma de chapadas e platôs, sendo que a dissecação da borda apresenta rebordos erosivos colinosos (MORAES, 2014).

Outro domínio amplamente presente na área de estudo é o "Domínio de Coberturas Sedimentares Proterozóicas, não ou muito pouco dobradas e metamorfizadas (DSP1)", caracterizado por possuir rochas dos grupos Ibiá e Bambuí, de idade neoproterozóica. Predominam diamictitos polimíticos, tilitos, siltitos, calcário cinza-escuro. Devido ao caráter sedimentar o relevo apresenta, na sua maior parte, superfícies aplainadas. Entretanto existem relevos em forma de inselbergs e relevos ruiniformes formados pelos afloramentos de calcário (MORAES, 2014). As cavernas da região estão majoritariamente associadas a este domínio.

Além desses três domínios principais, outros dois ocorrem de maneira irregular na área de estudo: o primeiro é o "Domínio das Sequências Sedimentares Proterozóicas Dobradas, Metamorfizadas de Baixo a Medio Grau (DSP2)". Neste domínio, há predominância de metacalcários, com intercalações subordinadas de metassedimentos síltico-argilosos e arenos, com relevo formado por degraus estruturais e rebordos erosivos (MORAES,2014). 0 último domínio presente na região é o “Domínio dos Complexos Granitoides intensamente Deformados: Ortognaisses (DCGR3)”. Este domínio é caracterizado por séries graníticas subalcalinas, como os tonalitos (MORAES, 2014).

A região em que se insere a área em estudo é uma região indicada para turismo de natureza pela Secretaria de Estado de Turismo do Distrito Federal, sendo o Distrito Federal (Brasília) o principal polo de demanda de turistas da região, de acordo com Cruz et al. (2012) (Figura 2). A visitação na região está relacionada com o geoturismo, em especial com a visita às cavernas presentes no parque estadual. 


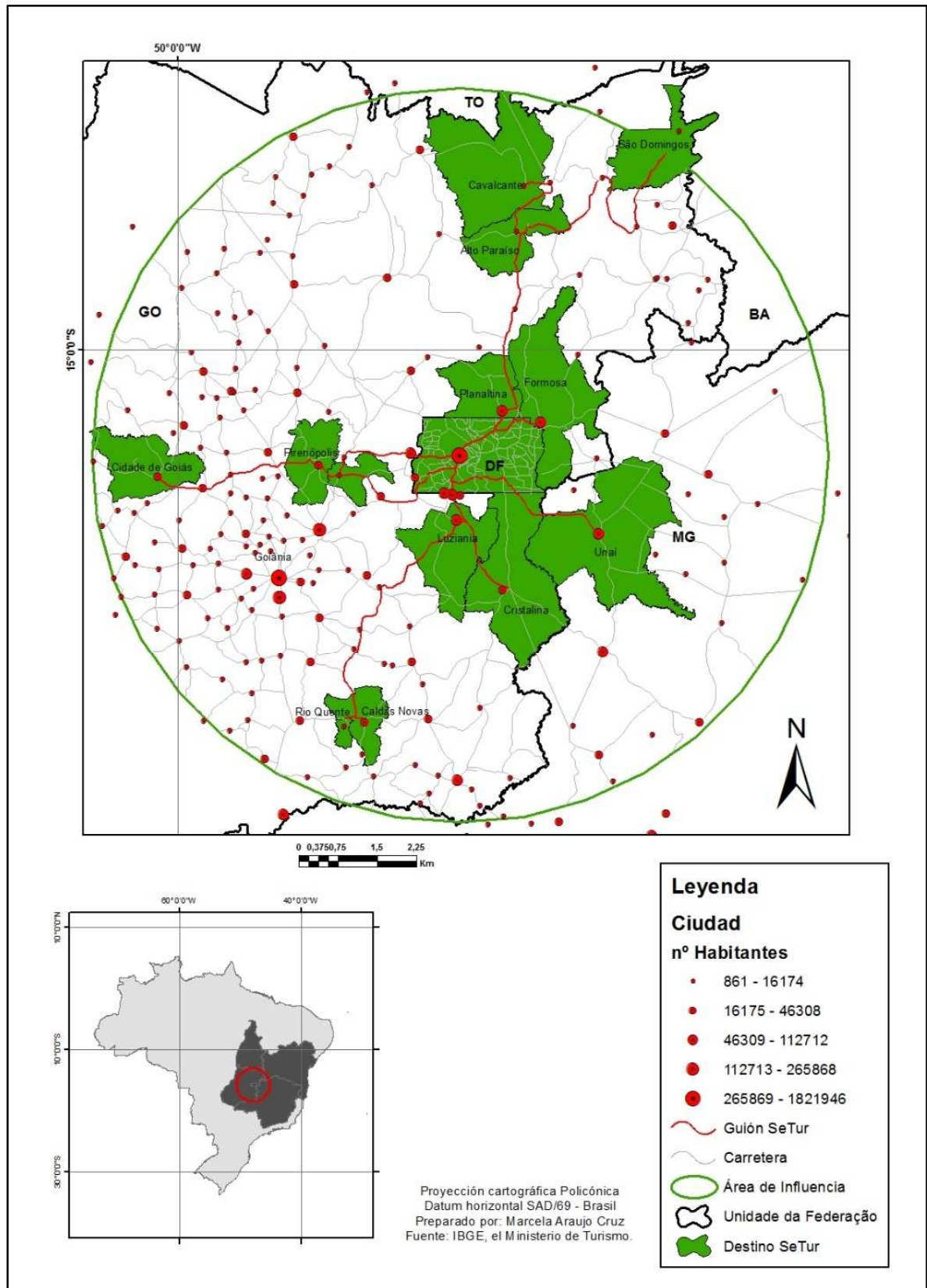

Figura 2. Áreas de indicação de turismo de natureza. Fonte: Cruz et al. (2012).

\subsection{Caracterização da caverna Terra Ronca}

A caverna Terra Ronca dá nome ao parque na qual se encontra, sendo a mais conhecida das cavernas da região. O seu nome é originário da fazenda na qual ela se encontra e deve-se ao som das tropas que passavam pela estrada que ligava São Domingos à Posse, pois o galope dos cavalos ecoava como um ronco ao passarem pela região.

A caverna possui uma das maiores bocas do país, com cerca de $100 \mathrm{~m}$ de largura por $84 \mathrm{~m}$ de altura, apresenta uma extensão de 750 m e é formada pelo rio Lapa. 
A caverna é formada pelos calcários do grupo Bambuí. A dissolução do calcário deu origem à cavidade que possui diversas formas características de ambientes cársticos, como estalactites, colunas, cortinas e travertinos.

O ambiente da caverna é bastante dinâmico, tendo alterações de acordo com as variações no regime hídrico. Durante o período chuvoso são carregadas grandes quantidades de materiais orgânicos originários das matas próximas, como terra, sementes e galhos. Quando o período de chuvas termina a altura das águas dos rios diminui, possibilitando a acumulação desses materiais em alguns locais, mas não necessariamente nos mesmos lugares todos os anos. A partir das fotografias a seguir, pode-se observar esta dinâmica. A primeira foto foi tirada durante o mês de setembro de 2012, nela se podendo observar a presença de um banco de areia (Figura 3), enquanto na fotografia seguinte, tirada no mês de julho de 2016, se nota a presença de matéria orgânica no lugar do banco de areia, com diversas plantas germinando (Figura 4).
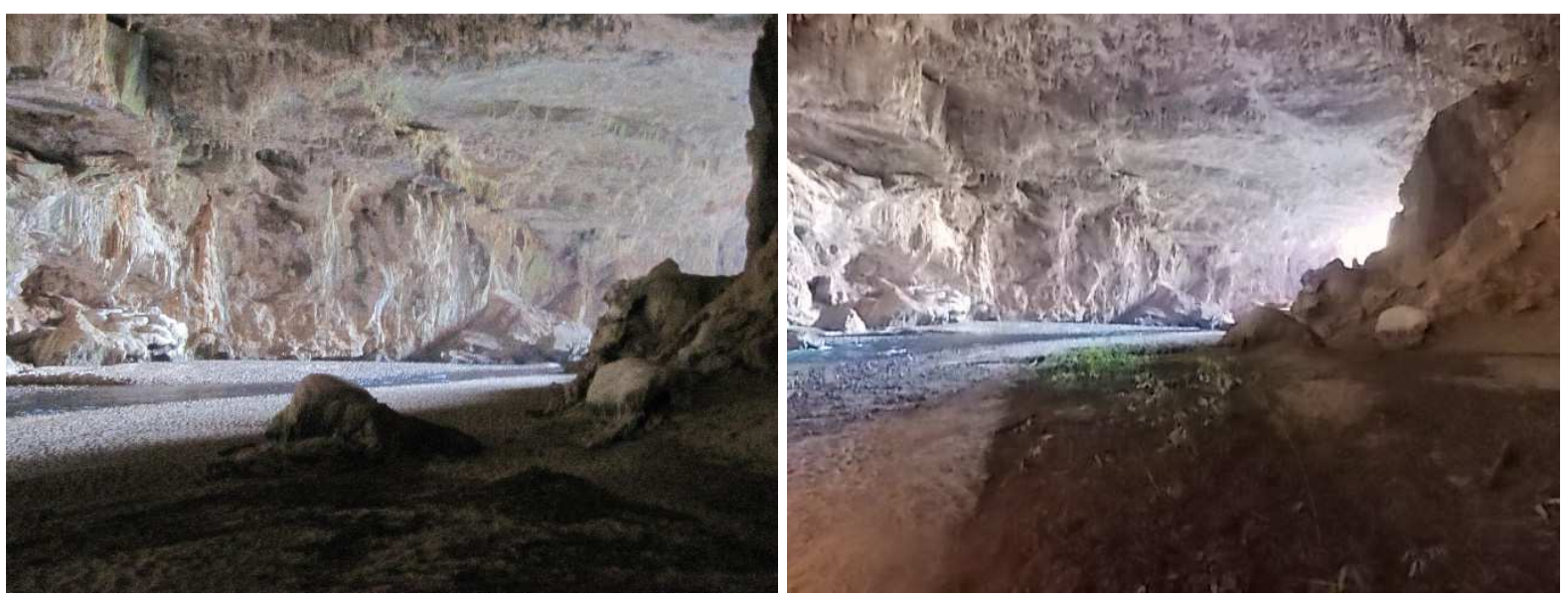

Figuras 3 e 4 - Mudanças na quantidade de matéria orgânica dentro da caverna. Fotografias Vinícius Galvão Zanatto. Setembro 2012 e Julho 2016.

$\mathrm{Na}$ entrada da caverna foi construído um altar em homenagem ao Bom Jesus da Lapa e todos os anos ocorre uma romaria, entre os dias 5 e 6 de agosto, que reúne centenas de fiéis (Figura 5). Durante as festividades, são realizadas uma missa e batizados. Existe uma pequena abertura próxima ao altar, conhecida como salão dos milagres, onde os romeiros depositam seus votos e objetos com a esperança de se curarem de alguma doença. 
A romaria é a principal festa da região, ocorre desde os anos 1930 e recebe pessoas de diversos municípios próximos, como Guarani de Goiás, Posse e laciara, que se deslocam a pé, a cavalo e de carro para cumprirem suas promessas.

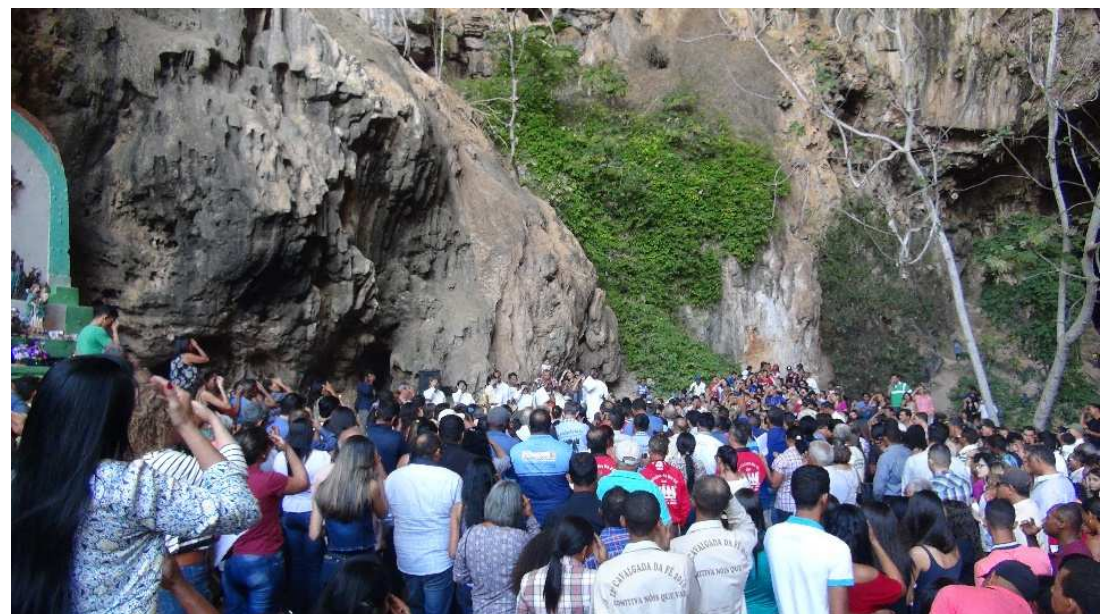

Figura 5 - Celebração Religiosa no Interior da Caverna próxima ao altar. Fotografia Vinícius Galvão Zanatto. Agosto de 2016.

É possível subir no topo da caverna Terra Ronca, por meio de uma trilha que segue pela lateral da caverna. A trilha se situa em uma área de floresta estacional, também conhecida como mata seca. A mata seca pode ser decídua ou semidecídua, ambas fitofisionomias do bioma Cerrado associadas aos ambientes com presença de calcário. Nessa trilha, podem-se observar as duas diferentes vegetações: a primeira semidecídua na parte baixa da trilha e a segunda decídua no topo da serra, acima da caverna, com presença de diversas bromélias e cactáceas.

\section{Procedimentos Metodológicos}

Fundamentamos este trabalho numa análise e revisão bibliográfica focada essencialmente na problemática da geodiversidade e do geoturismo, nas metodologias de avaliação dos impactos da atividade geoturística, bem como das caraterísticas da área de estudo.

Posteriormente procedemos à implementação do protocolo de avaliação rápida de impactos, elaborado a partir do modelo desenvolvido por Donato (2011) e Donato et al. (2014), complementado com entrevistas a informantes locais. 
Dessa forma, procurou-se compreender a situação atual do impacto existente na caverna Terra Ronca aliado a um conhecimento sobre a condução do turismo na região.

\subsection{Protocolo de avaliação rápida de impactos ao ambiente cavernícola (PAR-iac)}

O protocolo implementado no presente trabalho foi adaptado a partir do modelo proposto por Donato (2011) e Donato et al. (2014), para avaliação de impactos ambientais em cavernas. Esse procedimento foi aplicado à caverna Terra Ronca com o objetivo de avaliar os impactos causados no seu ambiente.

O protocolo encontra-se dividido em duas partes: na primeira parte são identificadas as possíveis atividades geradoras de impactos sobre os elementos geomorfológicos em análise. As atividades causadoras de impacto inicialmente selecionadas são: a mineração, a agricultura/criação de gado, o turismo/visitação desordenada, a urbanização, trabalhos de engenharia e a obstrução dos dutos de água (DONATO, 2011; DONATO et al., 2014). De referir que nessa parte podem ser selecionadas mais do que uma atividade geradora de impactos.

Na segunda parte do protocolo, de caráter essencialmente quantitativo, define-se um conjunto diversificado de tipos de impactos potencialmente nocivos para o ambiente/elementos geomorfológicos.

Os tipos de impacto são separados em 11 categorias, são elas:

- Completa destruição da caverna;

- Destruição parcial da caverna, quando parte da caverna é de alguma forma destruída;

- Mudanças na dinâmica hídrica, rebaixamento do aquífero, inundação, secagem de lagos e lagoas, destruição de áreas de recarga, obstrução de dutos e consequente inundação ou secagem;

- Mudanças no carste: rachaduras, deslocamentos, espeleotemas quebrados, descoloração dos espeleotemas, colapso das estruturas cársticas;

- Mudanças nas caraterísticas e estrutura do solo, como pisoteio de formações delicadas e compactação do solo; 
- Poluição sonora: sobreposição acústica e vibração;

- Assoreamento;

- Desmatamento da vegetação natural pelo fogo, redução da matéria orgânica, aumento de espécies exóticas, acidificação do solo, propagação de poluentes;

- Trabalhos de alvenaria, iluminação, calçadas, alterações microclimáticas;

- Visitação desordenada/ vandalismo: lixo, pichação e outros tipos de vandalismo;

- Alcance do impacto, tendo em conta a ação mais impactante: se não houver nenhum impacto, adiciona-se 0 pontos. Se o impacto é local, adicionam-se mais 5 pontos, se o impacto é regional, adicionam-se mais 10 pontos.

Quando o efeito é restrito para o local de ação, o impacto é definido como local. Regional refere-se ao efeito espalhado por uma área além da vizinhança imediata do local onde a ação acontece.

Os indicadores foram avaliados de acordo com o impacto sofrido e com 4 magnitudes possíveis (baixa, média, alta, extrema). À magnitude baixa são acrescentados 2 pontos, expressando que a destruição dos recursos naturais é pouco significativa, podendo ser revertida e não há possibilidade de esgotamento/destruição total do elemento geomorfológico. 4 pontos são acrescentados se for indicado que o impacto teve uma magnitude média, ou seja, quando os impactos são reversíveis a médio prazo (2 a 10 anos). A magnitude é alta quando os impactos nos recursos naturais são consideráveis, existindo a possibilidade de esgotamento e a recuperação apenas é viável a longo prazo (10 a 50 anos), sendo que, neste caso, são adicionados 6 pontos. À magnitude extrema são acrescentados 10 pontos. Nesta situação, os recursos foram degradados e exauridos, havendo pouca ou nenhuma possibilidade de recuperação do ambiente (DONATO, 2011; DONATO et al., 2014).

O resultado obtido é expresso em porcentagem e, a partir deste resultado pode-se classificar em seis categorias de níveis de impacto ambiental (DONATO, 2011; DONATO et al., 2014). São elas:

- Intacta (I): formas e processos geomorfológicos, comunidades biológicas naturais, populações e processos ecológicos aparentemente intactos, sem ameaças e alterações antrópicas. Pontuação $\leq 7$. 
- Estável (E): alterações antrópicas percetíveis, passíveis de interferir com formas e processos geomorfológicos e de provocar o declínio de populações locais. Processos ecológicos aparentemente intactos. Pontuação: 8 a 34 pontos.

- Vulnerável (VU): risco de extinção das formas e processos geomorfológicos, caso medidas de proteção não sejam tomadas. Habitats degradados. Pontuação: 35 a 61 pontos.

- Em perigo (EP): formas e processos geomorfológicos com alto risco de extinção. Perda e degradação de habitats, processos ecológicos comprometidos. Pontuação: 62 a 84 pontos.

- Criticamente em perigo (CP): formas e processos geomorfológicos com risco extremamente alto de extinção. Grandes alterações na paisagem do entorno ou matriz, comprometendo também a manutenção dos processos ecológicos e espécies nativas. Pontuação: 85 a 99.

- Extinta (EX): caverna extinta. Pontuação: 100.

\subsection{Entrevistas}

As entrevistas foram realizadas com a população local de forma não estruturada, com finalidade de compreender a relação das pessoas com as cavernas, com as unidades de conservação e qual a participação da comunidade no turismo da região. Dessa maneira, a entrevista funciona como meio de extrair informações subjetivas e pessoais, possibilita compreender as relações existentes entre os diversos grupos sociais em um determinado espaço e tempo, além de permitir a coleta de informações de como o sujeito entende e percebe sua realidade (DUARTE, 2004).

As entrevistas ocorreram entre os dias 13 e 15 de julho e no dia 5 agosto de 2016. Foram entrevistados 2 líderes comunitários, o primeiro considerado experiente no turismo da região, outro ligado aos extrativistas e população local, 2 guias de turismo locais e 1 que atua na região, mas não é morador local e o gestor do Parque Estadual de Terra Ronca. Os entrevistados foram escolhidos por possuírem diferentes olhares e abordagens para a problemática identificada na pesquisa. 


\section{Discussão}

\subsection{O Geoturismo na Região de Terra Ronca}

O turismo que ocorre na região de Terra Ronca pode ser enquadrado no âmbito do Geoturismo, porque as visitas na região ocorrem essencialmente por conta das características geológicas e geomorfológicas existentes.

Dowling (2010) aponta que o geoturismo apresenta 5 características fundamentais. A primeira característica é a necessidade de estar relacionado com as formas e processos geológicos e geomorfológicos. O segundo atributo é a sustentabilidade, isto é, o geoturismo tem que ser economicamente viável, ter capacidade para melhorar a vida da comunidade local e promover a geoconservação. O terceiro ponto é a informação científica, que se relaciona com a educação e a interpretação dos fenômenos da Terra, pois o geoturista tem desejo de interagir e compreender os fenômenos do ambiente terrestre. A quarta característica é o benefício para as comunidades locais, que devem participar do processo do geoturismo, que se torna benéfico para o ambiente, para a comunidade local e para os turistas. E a quinta característica é a experiência do turista, que está relacionada com a sua satisfação que permite viabilidade e a longevidade do mercado na área visitada.

A partir dessas características apontadas por Dowling (2010), pode-se realizar uma discussão sobre a forma como o geoturismo vem sendo conduzido na região de Terra Ronca.

O geoturismo que ocorre na região está intimamente relacionado com a presença na região de diversas cavernas de grandes dimensões. A sustentabilidade deste mercado pode ser questionada se avaliarmos a forma como o turismo vem sendo conduzido na região. Nenhuma das cavernas, nem as unidades de conservação, possuem plano de manejo, que é a ferramenta principal para regular as atividades e usos que se fazem nas áreas protegidas. Os estudos de capacidade de carga são fundamentais para compreender a capacidade das cavernas e, em especial, a caverna Terra Ronca, em receber visitantes sem que haja perda da geodiversidade e biodiversidade. No entanto, tais pesquisas nunca foram realizadas. 
No intuito de ordenar a atividade turística na região de Terra Ronca, foi estabelecido no ano de 2012 um plano emergencial de visitas turísticas para as cavernas de região, coordenado pela SEMARH, tendo sido definido um manual de operações no qual ficou estabelecido que apenas cinco cavernas presentes no Parque Estadual de Terra Ronca estariam aptas a receber visitantes, tendo em consideração a "logística de acesso, aspectos de fragilidade e beleza cênica, com potencial competitivo na oferta e segurança nas operações" (Goiás, 2012). São elas a caverna Terra Ronca, Terra Ronca II, São Bernardo, São Mateus e Angélica. O manual estabeleceu condições mínimas para que as atividades pudessem continuar a ser realizadas pela população. Cada caverna selecionada como apta a receber atividades turísticas possui um conjunto de regras específicas para que as visitas ocorram. Tais regulamentos são relativos aos percursos realizados dentro das cavidades e ao número de visitantes permitidos por grupo. Além das regras específicas, existem regras gerais relativas às medidas de segurança, regras para pesquisa e alterações antrópicas nas cavidades.

Contudo, no decurso das entrevistas efetuadas, alguns informantes apontaram que o turismo vem sendo conduzido de forma desordenada e que o órgão ambiental pouco atua na região de forma positiva para se melhorar este processo. Tem havido entrada de pessoas de fora da região para conduzir os turistas e que têm investido na região, nomeadamente com a abertura de pousadas, pelo que, nesse caso, acaba por excluir a população local da economia gerada por este mercado. Estes guias forasteiros também não se preocupam com a conservação dos ambientes cavernícolas, uma vez que tal fluxo tem gerado a destruição de diversos espeleotemas nas cavernas visitadas. Os guias locais são os grandes responsáveis pela conservação das cavernas e têm feito intervenções no sentido de restringir o acesso a algumas áreas para que não sejam danificadas. Apesar da entrada de guias de fora da região no mercado do turismo, a maior parte ainda é feita pelos guias locais, o que gera renda e dinamiza a economia local. Souza (2014) aponta a necessidade de capacitação dos guias locais, pois estes são muito envolvidos na conservação das cavernas e na importância delas para a comunidade, mas falta-lhes conhecimento sobre o grau de proteção da área em que estão inseridas, como por exemplo, o facto de se localizarem dentro de uma unidade de conservação, além de lacunas ao nível dos conhecimentos de geomorfologia e geologia.

Em relação aos turistas que visitam a região, a maioria destes possui idade entre 19 e 30 anos, fato que decorre essencialmente das dificuldades encontradas para realizar as trilhas 
nas cavernas, pois obriga a que os visitantes precisem estar em boas condições físicas (SOUZA, 2014). A maioria dos turistas são moradores do Distrito Federal, seguido do estado de Goiás e São Paulo (SOUZA, 2014). Quanto à escolaridade dos turistas que visitam a região, em um universo de 80 entrevistados, constatou-se $57,6 \%$ possuíam nível superior completo ou pós-graduação (SOUZA, 2014). Esse ponto aparece como um potencial não só no contexto dos processos de conservação, mas também no que respeita ao conhecimento de fenômenos do ambiente terrestre, isso porque esses turistas têm mais facilidade em compreender os elementos da geodiversidade em um contexto integrado.

\subsection{Avaliação dos Impactos na Caverna Terra Ronca}

Com o objetivo de avaliar os impactos exercidos sobre a caverna de Terra Ronca, implementamos o protocolo rápido de avaliação de impactos descrito na metodologia, que apresentamos na figura 6 .

Os impactos no ambiente cavernícola são principalmente observáveis no início da caverna, por ocorrer nessa área a maior parte das visitas, tanto turísticas como religiosas. As instalações antrópicas próximas ao altar estão danificadas, assim como uma das passagens construídas para auxiliar os turistas na travessia da caverna.

Existe uma pequena escada de concreto e com corrimão feito de cordas. Essas alterações no ambiente cavernícola são visualmente contrastantes com as características naturais da caverna. É necessário que se reforme a área do altar, para a segurança dos visitantes, por forma a diminuir o contraste com o ambiente da caverna e para diminuir os impactos no interior da caverna, pois os materiais que se desprendem dos tablados do altar correm o risco de cair dentro do rio que atravessa a caverna. A passagem que está danificada pode ser removida e trocada por algum material mais consistente com as características do ambiente. Da maneira que se encontra ela não só é uma visão desagradável, como também não proporciona segurança aos visitantes, pois as placas de madeira estão soltas.

A escada é uma intervenção permanente, pelo que sua remoção poderia causar mais impactos negativos do que benefícios, isso porque ela esta incrustada nas formações. Podese observar o pisoteio do chão, que causou a compactação do solo e a deformação de espeleotemas. Quanto mais se adentra a caverna, menores são os impactos antrópicos. Existem ainda algumas intervenções para auxiliar na travessia dos turistas dentro da caverna, a maioria constituída por cordas e correntes em que os visitantes se apoiam. 
Protocolo rápido de avaliação de impacto - Terra Ronca

\begin{tabular}{|c|c|c|c|}
\hline \multicolumn{3}{|l|}{ Atividade Causadora de impacto* } & Observacões \\
\hline \multicolumn{3}{|l|}{$\begin{array}{ll}\text { ( ) Mineração } & \text { ( } x \text { )Agricultura/Criação de gado } \\
\text { ( ) Obstrução } & \text { (x )Turismo/ Visitação desordenada } \\
\text { ( ) Urbanização } & \text { ( )Trabalho de Engenharia } \\
\text { *Pode haver mais de uma atividade causadora de impacto }\end{array}$} & \\
\hline \multicolumn{3}{|c|}{$\begin{array}{l}\text { Pontuação refere-se a magnitude do impacto, o que indica a gravidade do impacto sobre o } \\
\text { meio ambiente. A magnitude pode ser de } 4 \text { tipos: A) As ameaças aos recursos naturais são } \\
\text { insignificantes em relação à sua exaustão e o meio ambiente e comunidade degradação, } \\
\text { sendo reversível à curto prazo (até } 1 \text { ano); adicionar } 2 \text { pontos./ B) A utilização dos recursos } \\
\text { naturais é considerável, mas o esgotamento das reservas naturais não é possível, sendo a } \\
\text { degradação do meio ambiente e da comunidade reversível a médio prazo ( } 1 \text { a } 10 \text { anos), se } \\
\text { ações imediatas forem tomadas; adicionar } 4 \text { pontos./ C) A utilização dos recursos naturais é } \\
\text { considerável e o esgotamento das reservas naturais é possível, sendo a degradação do meio } \\
\text { ambiente e da comunidade reversível a longo prazo (10 a } 50 \text { anos), se ações imediatas } \\
\text { forem tomadas; adicionar } 6 \text { pontos./ D) Quando a ação causou a escassez de recursos } \\
\text { naturais e da degradação do meio ambiente e a comunidade não tem muitas chances de } \\
\text { reversibilidade; adicionar } 10 \text { pontos./ Se houver mais do que um componente a ser avaliado } \\
\text { em cada indicador, considerar a soma das pontuações, para valores inferiores a } 10 \text { e / ou } \\
\text { dar a pontuação mais alta (10), se a soma dos valores é maior do que } 10 \text {. }\end{array}$} & \\
\hline Tipo de impacto & $\begin{array}{l}\text { Pontuação } \\
\text { Estimada }\end{array}$ & Pontuação & \\
\hline $\begin{array}{l}\text { Completa destruição da caverna (se positivo, não é necessário } \\
\text { continuar a avaliação). }\end{array}$ & $0 / 100$ & 0 & \\
\hline Destruição parcial da Caverna. & $0 / 2 / 4 / 6 / 10$ & 4 & \\
\hline $\begin{array}{l}\text { Mudanças na dinâmica da água: diminuição do aquífero, } \\
\text { inundação, secagem de lagos e lagoas, destruição de áreas de } \\
\text { recarga, obstrução de dutos e consequente inundação ou secagem. }\end{array}$ & $0 / 2 / 4 / 6 / 10$ & 0 & \\
\hline $\begin{array}{l}\text { Mudanças no carste: rachaduras, descolamentos, espeleotemas } \\
\text { quebrados, descoloração dos espeleotemas colapso das estruturas } \\
\text { cársticas. }\end{array}$ & $0 / 2 / 4 / 6 / 10$ & 4 & \\
\hline $\begin{array}{l}\text { Mudanças na subsuperfície do solo: pisoteamento de formações } \\
\text { delicadas, compactação do solo. }\end{array}$ & $0 / 2 / 4 / 6 / 10$ & 4 & \\
\hline Poluição sonora: sobreposição acústica e vibração & $0 / 2 / 4 / 6 / 10$ & 2 & $\begin{array}{l}\text { Poluição sonora ocorre } \\
\text { em dias de festa. }\end{array}$ \\
\hline Assoreamento & $0 / 2 / 4 / 6 / 10$ & 4 & \\
\hline $\begin{array}{l}\text { Desmatamento da vegetação natural pelo fogo, redução da } \\
\text { matéria orgânica, aumento de espécies exóticas, acidificação do } \\
\text { solo, propagação de poluentes. }\end{array}$ & $0 / 2 / 4 / 6 / 10$ & 4 & \\
\hline $\begin{array}{l}\text { Trabalhos de alvenaria, iluminação, calçadas, alterações } \\
\text { microclimáticas. }\end{array}$ & $0 / 2 / 4 / 6 / 10$ & 6 & \\
\hline $\begin{array}{l}\text { Visitação desordenada/ vandalismo: lixo, pichação e outros tipos } \\
\text { de vandalismo. }\end{array}$ & $0 / 2 / 4 / 6 / 10$ & 2 & \\
\hline $\begin{array}{l}\text { Alcance do impacto, tendo em conta a ação mais impactante: Se } \\
\text { não houver nenhum impacto - adicione } 0 \text { pontos. Se o impacto é } \\
\text { local - adicionar mais } 5 \text { pontos. Se o impacto é regional - } \\
\text { adicionar mais } 10 \text { pontos. Nota: local - quando o efeito é restrito } \\
\text { para o local de ação; Regional - quando o efeito é espalhado por } \\
\text { uma área além da vizinhança imediata do local onde a ação } \\
\text { acontece. }\end{array}$ & $0 / 5 / 10$ & 10 & \\
\hline Total & & 40 & \\
\hline
\end{tabular}

Figura 6 - Protocolo de Avaliação Rápida de Impactos ao Ambiente Cavernícola, aplicado à Caverna Terra Ronca. Adaptado de Donato (2011) e Donato et al. (2014). 
A escada é uma intervenção permanente, pelo que sua remoção poderia causar mais impactos negativos do que benefícios, isso porque ela esta incrustada nas formações. Podese observar o pisoteio do chão, que causou a compactação do solo e a deformação de espeleotemas. Quanto mais se adentra a caverna, menores são os impactos antrópicos. Existem ainda algumas intervenções para auxiliar na travessia dos turistas dentro da caverna, a maioria constituída por cordas e correntes em que os visitantes se apoiam.

A parte posterior da caverna Terra Ronca está mais bem preservada que sua entrada. Existe uma grande presença de estalactites e uma maior variedade de formações. A mata de galeria desta área também está mais preservada (Figura 7). O pisoteio do solo ocorre somente na trilha em que a visitação acontece.

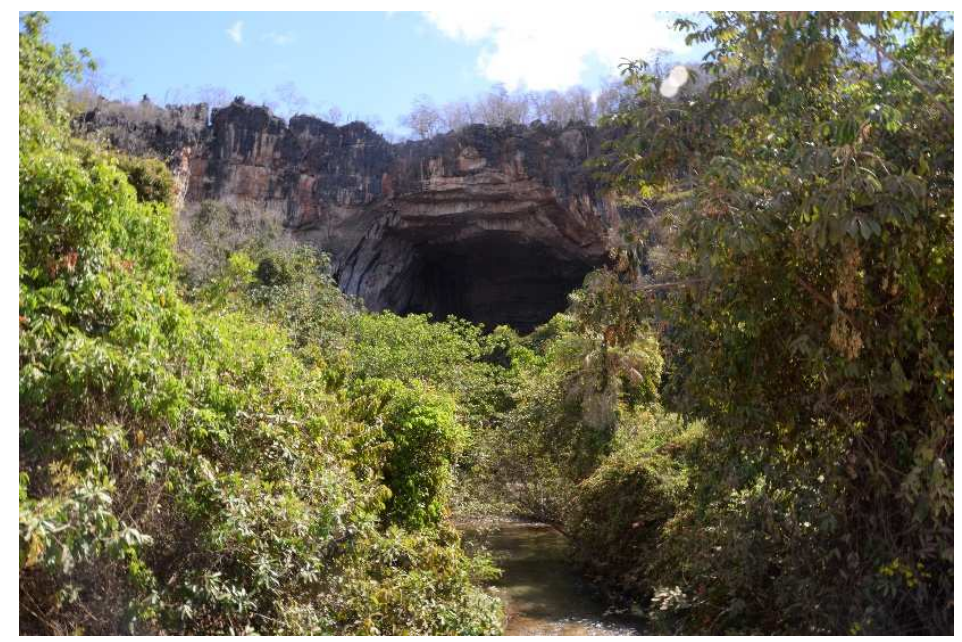

Figura 7. Boca da caverna Terra Ronca e perspetiva da mata galeria. Fotografia: Vinícius Galvão Zanatto, Setembro 2017.

Nos arredores da caverna ocorre a criação de gado. Frequentemente esses rebanhos saem dos pastos delimitados nas fazendas e dirigem-se ao rio Lapa, que forma a caverna Terra Ronca. Os rebanhos causam a compactação do solo pelo pisoteio e a destruição da vegetação ripária, aproximam-se muito da caverna, causando impacto direto em todo o geosistema.

As principais alterações estão relacionadas com o meio abiótico da caverna, como sejam a degradação dos espeleotemas e o pisoteio e compactação do solo. Foram encontrados impactos relacionados com a degradação da vegetação próxima da cavidade avaliada, como a mata de galeria parcialmente degradada, próxima à entrada da caverna, e a ocorrência de incêndios na floresta estacional decidual presente acima da cavidade. 
A poluição sonora ocorre devido à estrada existente próximo da caverna, não sendo, entretanto, significativa. O maior impacto causado pela poluição sonora ocorre durante os festejos do Bom Jesus da Lapa no mês de agosto, quando a missa ocorre dentro da caverna e há uma grande aglomeração de pessoas dentro e nos arredores da caverna (Figura 5). 0 barulho é visivelmente impactante na avifauna presente na caverna, em especial as araras vermelhas (Ara Chloropterus) que nidificam nos paredões da caverna. Normalmente elas não são facilmente avistadas. Porém, no dia da festa, elas ficam agitadas e são vistas com frequência próximas aos ninhos localizados na borda do afloramento em que se encontra a caverna.

Outro impacto percetível é o assoreamento do rio que forma a caverna. Tal impacto não é causado pela visitação desordenada e sim pelo uso da terra que é feito a montante, além de ser um impacto causado pelos incêndios florestais que atingiram o PETER no ano de 2017. Os incêndios retiram a vegetação que segura o solo e sem esta proteção os sedimentos são transportados para o rio causando seu assoreamento, impactando diretamente nos processos hidrológicos que ocorrem na caverna.

A visitação da Caverna Terra Ronca ocorre sem a presença de guias, devido à facilidade do seu acesso e à cultura local de devoção aí existente. Os guias são procurados somente no momento da travessia da cavidade. Devido a essa falta de acompanhamento, muitos visitantes deixam lixo espalhado na entrada da caverna, causando poluição

Os impactos observados na caverna Terra Ronca se estendem além das imediações da caverna. Seguindo o curso do rio Lapa, a mata de galeria encontra-se parcialmente preservada, tendo ocorrido, no entanto, desmoronamentos em algumas áreas, impactando os paredões de calcário, a mata de galeria e os recursos hídricos.

A partir do protocolo de avaliação rápida de impactos na caverna Terra Ronca, verifica-se que as principais atividades causadoras de impacto na caverna são a criação de gado e a visitação desordenada. Da avaliação efetuada, constata-se que ela foi classificada como vulnerável, atingindo 40 pontos na escala determinada de 100 . Essa pontuação indica a perda de habitat e impactos antrópicos percetíveis. Devido ao tamanho da geoforma em análise do afloramento não há risco de desaparecimento. No entanto, as formas internas da caverna e os processos relativos à formação destes estão comprometidos. 
A caverna avaliada está inserida em um ambiente heterogêneo, com a presença de outras cavernas próximas, o que potencializa a necessidade de conservação deste ambiente cárstico singular. Outro aspeto significativo é a presença de fauna no interior da caverna, uma vez que existem populações de animais troglófilos e troglóbios, como a espécie eusarcus sp, da ordem dos opiliones (SIMÕES, 2013), que nesse caso é uma espécie restrita à ambientes subterrâneos.

Visto isso, algumas considerações devem ser feitas a respeito da manutenção dos processos geoecológicos visando a conservação e proteção da respetiva caverna.

Como apontado no protocolo, a mata de galeria da entrada da caverna está degradada, havendo necessidade de estabelecer um projeto para a recuperação dessa mata que é fundamental para a saúde da caverna avaliada. $\mathrm{O}$ isolamento desse local já traria benefícios imediatos para a mata de galeria, pois impediria a aproximação dos rebanhos de gado do corpo hídrico nas proximidades da caverna e possibilitaria a regeneração dessa área.

As visitas ocorrem de maneira desordenada, pelo que estabelecer um programa educativo para os guias da região é fundamental, para que esses agentes tenham consciência e capacidade para exercer suas atividades causando o menor impacto possível na caverna. Devido ao grande apelo cultural que a caverna de Terra Ronca possui, isso deve ser utilizado como uma potencialidade educativa. O desenvolvimento de iniciativas do órgão demonstrando a importância das cavernas é essencial, em especial se realizadas nos dias da romaria, momento esse que reúne uma grande quantidade de pessoas na região.

\section{Considerações finais}

O Manual de Operações do Plano Emergencial de Visitas Turísticas estabeleceu algumas regras para as atividades dentro das cavernas do parque, entretanto o documento peca por não possuir mais informações sobre as cavidades em destaque nem sobre como as visitações devem ocorrer, o limite de visitantes em cada caverna foi estabelecido a partir de reuniões com os guias, com a gestão do parque e especialistas do Centro Nacional de 
Pesquisa e Conservação de Cavernas (CECAV). Essa iniciativa é válida, pois inclui os maiores interessados na atividade turística nas discussões de como este deve ser conduzido, porém não são utilizados trabalhos técnicos para definir a quantidade de visitantes são possíveis para cada caverna.

Devido aos impactos avaliados a partir do protocolo, fica exposta a necessidade de criar mecanismos de conservação que vão além do plano emergencial, mas para que isso ocorra é necessário que se estabeleça os planos de manejo das cavernas abertas para o turismo, esse documento deve conter as prioridades de ação para cada caverna e estabelecer um programa de monitoramento do estado de conservação de cada uma.

A partir do exposto, é possível constatar que o turismo não vem sendo manejado de forma adequada na região de Terra Ronca. O protocolo de avaliação demonstrou que a caverna amostrada pode ser considerada estável quanto aos processos ecológicos existentes. No entanto, isso não significa que não ocorram impactos e que estes devem ser revertidos ou mitigados, para que os processos continuem ocorrendo. O protocolo mostrou-se uma ferramenta funcional e que pode e deve ser replicado nas outras cavernas da região, para que ações de conservação possam ser tomadas de forma mais efetiva e direta no que diz respeito aos impactos ambientais, essa ferramenta é capaz de auxiliar na manutenção do plano emergencial e dos planos de manejo, já que apresenta novas informações sobre a conservação das cavernas da área de estudo.

O grande desafio que se coloca na região é aliar a conservação, a visitação e promover o desenvolvimento da comunidade local. Diversas pessoas estão envolvidas no turismo, mas não possuem capacitação formal sobre os processos geológicos e geomorfológicos existentes, o que poderia melhorar a experiência do visitante.

O acesso à região também é difícil, passa pelo nível estadual que deveria prezar pela conservação e manutenção da rodovia. O Estado (esferas federal e estadual) deveria fortalecer os órgãos ambientais para que estes possam ser mais atuantes nas áreas de monitoramento, fiscalização e educação. A produção dos planos de manejo das unidades envolvidas é fundamental, pois é nesse instrumento que estão presentes as principais características, prioridades e necessidades das UC's. 


\section{Referências bibliográficas}

AZEVEDO, Úrsula Ruchkys de. Patrimônio Geológico e Geoconservação no Quadrilátero Ferrífero, Minas Gerais: Potencial para a Criação de um Geoparque da UNESCO. Tese de Doutorado. Universidade Federal de Minas Gerais, 2007.

CADASTRO NACIONAL DE CAVERNAS, 2016. http://cnc.cavernas.org.br/. (Consultado em 04 de maio de 2016).

CARVALHO, Gisélia Lima. Entre a pobreza econômica e o patrimônio ambiental/cultural: desafios e possibilidades do turismo no nordeste goiano, In Observatório Geográfico de Goiás, 2004, pp. 1 - 19. https://observatoriogeogoias.iesa.ufg.br/up/215/o/Carvalho giselia lima pobreza econ mica.pdf (Consultado em 27 de agosto de 2016).

CARVALHO, Gisélia Lima. O turismo no nordeste goiano e a possibilidade de valorização da natureza e da cultura do Cerrado. In, Almeida, Maria Geralda, Tantos cerrados: múltiplas abordagens sobre a biogeodiversidade e singularidade cultural, Goiânia, Editora Vieira, 2005, pp. 251 - 270.

CRUZ, Marcela Araújo, STEINKE, Valdir Adilson, SOBRINHO, Luis Fernando Araujo. El Geoturismo en el Entorno del Distrito Federal (BRASIL): un analisis prévio a la planificación turística regional, In Estudios y Perspectivas en Turismo. Vol. 21, 2012, pp. 778 - 797.

DONATO, Christiane Ramos. Análise de impacto sobre as cavernas e seu entorno no município de Laranjeiras, Sergipe, Dissertação de Mestrado em Desenvolvimento e Meio Ambiente, Universidade Federal de Sergipe, São Cristovão, Sergipe, 2011.

DONATO, Christiane Ramos, RIBEIRO, Adauto de Souza, SOUTO, Leandro de Sousa. A conservation status index, as an auxiliary tool for the management of cave environments. International Journal of Speleology, Vol. 43, N³, 2004, pp. $315-322$.

DOWLING, Ross K. Geotourism's Global Growth. In Geoheritage, Vol. 3, N 1, 2010, pp. 1 - 13.

DUARTE, Rosália. Entrevistas em pesquisas qualitativas. In Educar, Vol. 24, 2004, pp. 213 - 225.

GOIÁS, Manual de Operações do Plano Emergencial de Visitas Turísticas: Cavernas PETER - Parque Estadual de Terra Ronca - São Domingos, SEBRAE Goiás, 2012.

GORDON, John E., BARRON, Hugh F. The role of geodiversity in delivering ecosystem services and benefits in Scotland. Scottish Journal of Geology, 49 (1), 2013, pp. 41 - 58. https://doi.org/10.1144/sjg2011-465

GRAY, Murray. Other Nature: Geodiversity and Geosystem Services. In Environmental Conservation, Vol. 38, № 3, 2011, pp. $271-274$.

HERMUCHE, Potira Meirelles, Modelagem da Paisagem da Floresta Estacional Decidual no Vão do Paranã, Goiás, Tese de Doutorado em Ciências Ambientais, Universidade Federal de Goiás, Goiânia, 2010.

HOBO, Fernanda Etsumi. Viajando por paisagens naturais: a espeleologia como experiência turística, Dissertação de mestrado em Geografia Física, Universidade de São Paulo, São Paulo, 2011.

HOSE, T. A. Selling the Story of Britain's Stone. Environmental Interpretation, Vol. 10, No. 2, 1995, pp. 16 - 17.

IBGE, Zoneamento Geoambiental e Agroecológico do Estado de Goiás: Região Nordeste, 1995.

LOBO, Heros Augusto Santos et al. Projection of tourist scenarios on to fragility maps: Framework for determination of provisional tourist carrying capacity in a Brazilian show cave, In Tourism Management, Vol. 35, 2013, pp. $234-243$.

MATTEUCCI, Magda Beatriz de Almeida. Hóspedes de si mesmos: um estudo socioambiental sobre a unidade de conservação Parque Estadual de Terra Ronca - GO, Tese de Doutorado, Centro de Desenvolvimento Sustentável, Universidade de Brasília, Brasília, 2003.

MORAES, Juliana Maceira. Geodiversidade do Estado de Goiás e do Distrito Federal, CPRM, Goiânia, 2014.

NASCIMENTO, M. A. L. do, AZEVEDO, Ú. R. de, NETO, V. M. Geoturismo: Um Novo Segmento do Turismo, PUC Minas - Revista de Turismo - Vol. 2, N¹, 2007. 
NUNES, Fabrizia Gioppo. Análise exploratória espacial de indicadores de desenvolvimento socioambiental das regiões de planejamento do norte e nordeste goiano, In Ateliê Geográfico, Vol. 7, N 1, 2013, pp. 237 - 259

RODRIGUES, M. L. Geodiversidade, Património Geomorfológico e Geoturismo. CEG, UL, 2009.

SIMÕES, Luiza Bertelli, Biodiversidade da Fauna Subterrânea na Área Cárstica de São Domingos, Nordeste de Goiás: Relevância Versus Visibilidade de Táxons, Dissertação de Mestrado, Universidade Federal de São Carlos, São Carlos, 2013.

SOUZA, Gleydson Herbete de. Identificação da Atividade Turística e Fomento do Ecoturismo no Parque Estadual de Terra Ronca - GO, Centro Universitário de Brasília, Pós-Graduação em Análise Ambiental e Desenvolvimento Sustentável, Brasília, 2014.

STANLEY, M. Geodiversity. In Earth Heritage, Vol. 14, 2000, pp. 15 - 18.

VIEIRA, A. Serra de Montemuro: dinâmicas geomorfológicas, evolução da paisagem e património natural. Tese de Doutoramento. Universidade de Coimbra, 2008.

VIEIRA, A. O Património Geomorfológico no contexto da valorização da geodiversidade: sua evolução recente, conceitos e aplicação. Cosmos, 7(1), 2014, pp. 28 - 59. 